This document is confidential and is proprietary to the American Chemical Society and its authors. Do not copy or disclose without written permission. If you have received this item in error, notify the sender and delete all copies.

\title{
Photoinduced Electron Transfer Coupled to Donor Deprotonation and Acceptor Protonation in a Molecular Triad Mimicking Photosystem II
}

\begin{tabular}{|r|l|}
\hline Journal: & Journal of the American Chemical Society \\
\hline Manuscript ID & ja-2017-08761y.R1 \\
\hline Manuscript Type: & Communication \\
\hline Date Submitted by the Author: & $12-S e p-2017$ \\
\hline Complete List of Authors: & $\begin{array}{l}\text { Pannwitz, Andrea; Universitat Basel, Department of Chemistry } \\
\text { Wenger, Oliver; University of Basel, Department of Chemistry }\end{array}$ \\
\hline
\end{tabular}

\section{SCHOLARONE \\ Manuscripts}


In photosystem II, electrons are transferred over long distances upon photoexcitation, leading to temporary separation of redox equivalents. Many artificial donor-sensitizer-acceptor compounds emulated the primary charge separation events, and in numerous cases long-lived electron-hole pairs were formed. ${ }^{1}$ However, in photosystem II, there is not just simple electron-hole generation but instead the resulting reduction and oxidation products both undergo proton-coupled electron transfer (PCET) for further stabilization. ${ }^{2}$ Specifically, tyrosine $\mathrm{Z}$ oxidation $\left(\mathrm{Y}_{\mathrm{Z}}\right.$ in Figure $\left.1 \mathrm{a}\right)$ is coupled to deprotonation yielding a neutral phenoxyl radical, and the plastoquinone $B$ acceptor $\left(Q_{B}\right.$ in Figure $\left.1 \mathrm{a}\right)$ is protonated upon reduction. ${ }^{2-3}$ We present the first artificial donor-sensitizeracceptor compound that is able to emulate this entire series of events seen in photosystem II, namely photoinduced long-range electron transfer coupled to proton release at the donor in combination with proton uptake at the electron acceptor. The net result is the formation of a long-lived radical pair state, instead of the simple electron-hole separation observed many times before (Figure $1 b$ ). While there have been prior studies in which photoinduced electron transfer was coupled to proton transfer at either the donor or the acceptor site, ${ }^{4}$ to the best of our knowledge, our triad is the first purely molecular system in which PCET reactivity is possible at both reactants. Moreover, in many previously investigated systems phototriggered PCET actually occurred between species in their electronic ground states (e. g. between $\mathrm{Ru}(\mathrm{III})$ complexes and phenols), and there was no intramolecular energy

\begin{abstract}
The first artificial donor-sensitizer-acceptor compound in which photoinduced long-range electron transfer is coupled to donor deprotonation and acceptor protonation is reported.
The long-lived photoproduct stores energy in the form of a radical pair state in which the charges of the donor and the acceptor remain unchanged, much in contrast to previously investigated sys-
tems that exhibit charge-separated states comprised of electronhole pairs. This finding is relevant for light-driven accumulation charge can be avoided yet light energy can be stored. Protoncoupled electron transfer (PCET) reactions at a phenol donor and a monoquat acceptor triggered by excitation of a $\mathrm{Ru}(\mathrm{II})$ sensitizer
enable this form of photochemical energy storage. Our triad emulates photosystem II more closely than previously investigated systems, because tyrosine $\mathrm{Z}$ is oxidized and deprotonated, whereas plastoquinone $\mathrm{B}$ is reduced and protonated.
\end{abstract}

storage. $^{4 \mathrm{a}, \mathrm{b}, 4 \mathrm{f}, 4 \mathrm{k}}$ Some of the previously investigated systems exhibited charge-shift reactions without any charge build-up.
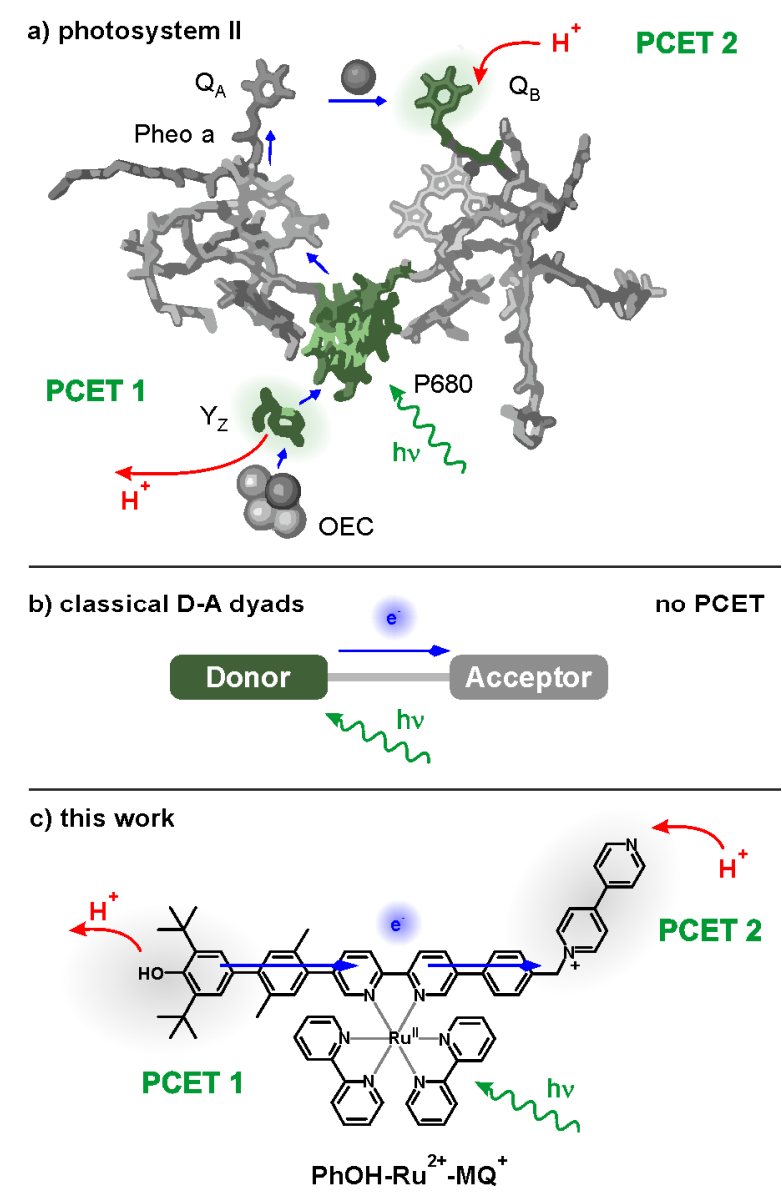

Figure 1. (a) Primary and secondary electron transfer events (blue arrows) in photosystem II after excitation of P680 (green central part). PCET occurs at tyrosine $\mathrm{Z}$ (green, lower left) and at plastoquinone B (green, upper right). ${ }^{3}$ (b) Generic donor-acceptor compound exhibiting simple electron-hole separation. (c) Investigated triad comprised of a phenol donor $(\mathrm{PhOH})$ resembling tyrosine $\mathrm{Z}$ (PCET 1), a Ru(II) sensitizer mimicking the function of $\mathrm{P} 680$, and a monoquat acceptor $\left(\mathrm{MQ}^{+}\right)$playing the role of plastoquinone $\mathrm{B}$ with regard to uptake of one electron and one proton (PCET 2). 
Our key compound is a molecular triad (Figure 1c) comprised of a $\mathrm{Ru}(\mathrm{bpy})_{3}{ }^{2+}$ (bpy $=2,2^{\prime}$-bipyridine) photosensitizer, a monoquat (MQ ${ }^{+}, N$-methyl-4,4'-bipyridinium) acceptor, and a ditert-butylphenol $(\mathrm{PhOH})$ donor. Its synthesis including full characterization is reported in the Supporting Information (page S2S13). In $\mathrm{CH}_{3} \mathrm{CN}$, excitation of the $\mathrm{Ru}(\mathrm{II})$ sensitizer at $532 \mathrm{~nm}$ merely leads to ${ }^{3}$ MLCT luminescence and no photochemistry occurs (SI page S15-S16). Not surprisingly, in order for the anticipated reductive and oxidative PCET events to become viable photochemical reaction pathways, acids and bases must both be simultaneously present. Pyridine (py) turned out to be optimal as solvent, and through addition of some triflic acid, pyridinium $\left(\mathrm{pyH}^{+}\right)$was formed $(0.22 \mathrm{M})$. The resulting $\mathrm{py} / \mathrm{pyH}^{+}$mixture was a suitable organic buffer for our spectroscopic studies. UV-Vis and ${ }^{1} \mathrm{H}-\mathrm{NMR}$ data indicate that the phenolic unit of the triad remains largely protonated in this solvent while the $\mathrm{MQ}^{+}$unit remains unprotonated (SI page S17-S20).

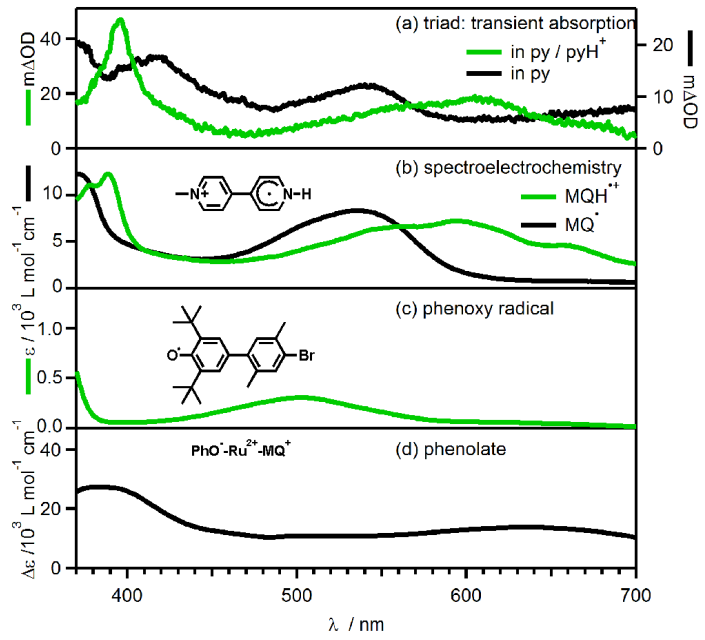

Figure 2. (a) Transient absorption spectra after excitation of the triad at $532 \mathrm{~nm}$ in pyridine with $0.22 \mathrm{M}$ pyridinium (green, $34 \mu \mathrm{M}$ triad), and in neat pyridine (black, $55 \mu \mathrm{M}$ triad). Detection occurred in a 200 -ns time window $2 \mu$ s after excitation with pulses of $\sim 10$ ns duration. (b) Electrochemically generated spectra of $\mathrm{MQH}^{\cdot+}$ (green) and MQ (black) using a reference compound (inset) in $\mathrm{CH}_{3} \mathrm{CN}$ with $0.1 \mathrm{M} \mathrm{TBAPF}_{6}$. (c) Spectrum of chemically generated $\mathrm{PhO}^{\circ}$ using a reference compound (see inset) in $6: 1$ toluene/pyridine. Extinction coefficients were estimated based on previously published spectra (SI pages S21-S22). ${ }^{5}$ (d) Difference spectrum obtained from a solution of the triad in $\mathrm{CH}_{3} \mathrm{CN}$ before and after addition of 4 eq. TBAOH, in order to determine the spectral contribution of $\mathrm{PhO}^{-}$.

Selective photoexcitation of the $\mathrm{Ru}(\mathrm{II})$ sensitizer of the triad at $532 \mathrm{~nm}$ in the $\mathrm{py} / \mathrm{pyH}^{+}$mixture leads to the formation of a longlived photoproduct exhibiting the transient absorption spectrum shown as a green trace in Figure 2a. This spectrum is dominated by the spectral signature of $\mathrm{MQH}^{\cdot+}$, i. e., the reduced and protonated form of the monoquat acceptor resembling the well-known methylviologen radical monocation spectrum. ${ }^{5 \mathrm{a}, 6}$ Comparison to the spectro-electrochemical data in Figure $2 b$ (green trace), for which a $\mathrm{MQ}^{+}$reference compound (see inset) was protonated and reduced (see SI pages S21-S22 for details), corroborates this assignment. In neat py without $\mathrm{pyH}^{+}, \mathrm{MQ}^{*}$ is instead formed, as seen from comparison of the black traces in Figure 2a (transient absorption) and Figure $2 \mathrm{~b}$ (spectro-electrochemistry). The same observation is made with other bases, for example with pyrrolidine (see SI pages S35-S36).

While the formation of $\mathrm{MQH}^{\cdot+}$ from $\mathrm{MQ}^{+}$in the $\mathrm{py} / \mathrm{pyH}^{+}$solution is immediately evident, identification of the oxidation product requires somewhat more effort. The spectral signature of the anticipated phenoxyl radical $\left(\mathrm{PhO}^{\circ}\right)$ was determined by oxidizing a suitable reference compound under alkaline conditions (Figure $2 \mathrm{c}$, see SI page S23 for details). The main absorption bands of $\mathrm{PhO}^{\circ}$ overlap spectrally with those from $\mathrm{MQH}^{{ }^{+}}$, and the extinction coefficients of $\mathrm{PhO}^{*}$ at the relevant wavelengths are about an order of magnitude weaker than those of $\mathrm{MQH}^{*+}$ (Figure $2 \mathrm{~b} / \mathrm{c}$ ), ${ }^{5 \mathrm{~b}, \mathrm{c}}$ hence direct observation of $\mathrm{PhO}^{*}$ is hampered.

Several lines of evidence nevertheless clearly indicate that $\mathrm{PhO}^{\circ}$ is formed after photoexcitation of the triad. First of all, the photoproduct observed in de-aerated py/pyH $\mathrm{H}^{+}$at $25^{\circ} \mathrm{C}$ has a lifetime $(\tau)$ of $1.9 \pm 0.2 \mu \mathrm{s}$ (see below), compatible with the $\mu \mathrm{s}$-lifetimes of long-range electron-hole separation in comparable triarylamine$\mathrm{Ru}(\mathrm{II})$-quinone compounds and other related triads. ${ }^{7}$ By contrast, in a reference dyad comprised of only the $\mathrm{Ru}(\mathrm{II})$ sensitizer and the $\mathrm{MQ}^{+}$acceptor no long-lived photoproduct is formed ( $\tau \leq 10 \mathrm{~ns}$, SI pages S37-S40), indicating that the phenolic reaction site plays a key role in stabilizing the $1.9 \mu \mathrm{s}$-photoproduct observed for the triad. Furthermore, according to electrochemical studies phenols undergo concerted PCET in presence of pyridine, leading to a substantial lowering of the oxidation potential due to coupled proton release. ${ }^{8}$ It is clear that $\mathrm{PhOH}$ cannot be oxidized to $\mathrm{PhOH}^{\cdot+}$ by ${ }^{3} \mathrm{MLCT}$-excited Ru(bpy) ${ }_{3}{ }^{2+}$ due to lack of sufficient driving-force $\left(\Delta \mathrm{G}_{\mathrm{ET}}^{\circ}=+0.5 \mathrm{eV}\right.$; SI page $\left.\mathrm{S} 29\right)$, but oxidation to $\mathrm{PhO}^{\circ}$ is readily possible $\left(\Delta \mathrm{G}_{\text {PCET }}^{\circ}=-0.4 \mathrm{eV}\right.$; see below $){ }^{4 \mathrm{a}-\mathrm{m}, 9}$ Lastly, in neat pyridine a transient absorption band appearing at $420 \mathrm{~nm}$ (black trace in Figure 2a) signals the formation of phenolate $\left(\mathrm{PhO}^{-}\right)$as an additional photoproduct to the abovementioned $\mathrm{MQ}^{\circ}$ species formed under these acid-free conditions (SI page S32 for further details). The $\mathrm{PhO}^{-}$species appears as a result of initial formation of $\mathrm{PhO}^{\circ}$ and $\mathrm{Ru}(\mathrm{bpy}){ }_{3}{ }^{+}$by reductive ${ }^{3} \mathrm{MLCT}$ quenching and subsequent rapid thermal reverse electron transfer leading to $\mathrm{PhO}^{-}$and $\mathrm{Ru}(\mathrm{bpy})_{3}{ }^{2+}$ in a subset of triads (SI page S31). The net result is simple proton release at the phenol upon $\mathrm{Ru}(\mathrm{II})$ excitation, and such apparent photoacid behavior has been reported previously for Ru(II)-phenol and Re(I)-phenol dyads. ${ }^{10}$ Thus, the $\mathrm{PhO}^{-}$signature at $420 \mathrm{~nm}$ indicates the intermediacy of $\mathrm{PhO}^{\circ}$ in neat pyridine.

Given these three lines of evidence $(1.9 \mu$ s lifetime of the triad photoproduct compared to sub-10-ns lifetimes of several Ru(II)$\mathrm{MV}^{2+}$ dyads (SI pages S37-40); ${ }^{11}$ known PCET chemistry of $\mathrm{PhOH}$ in presence of pyridine, ${ }^{8,9} \mathrm{PhO}^{-}$signature in neat py signaling the intermediacy of $\mathrm{PhO}^{\circ}$ ) it is safe to conclude that the main photoproduct after excitation of the triad in $\mathrm{py} / \mathrm{pyH}^{+}$is indeed comprised of $\mathrm{PhO}^{\circ}$ and $\mathrm{MQH}^{*+}$.

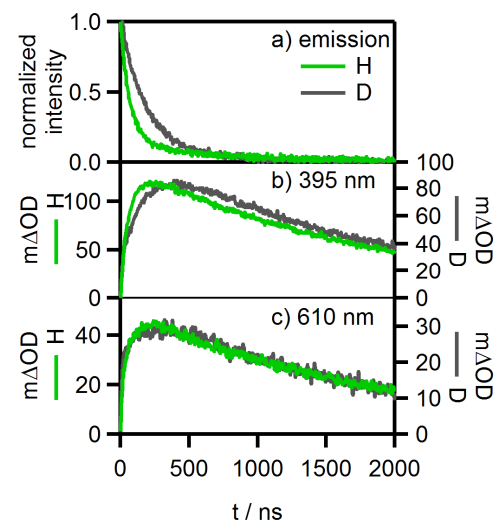

Figure 3. (a) Temporal evolution of luminescence recorded at $630 \mathrm{~nm}$. (b, c) Temporal evolution of transient absorption signals at $395 \mathrm{~nm}$ and $610 \mathrm{~nm}$. Excitation of $34 \mu \mathrm{M}$ triad in de-aerated $\mathrm{py} / \mathrm{pyH}^{+}$(green) or py/pyD ${ }^{+}$(gray) occurred at $532 \mathrm{~nm}$ with laser pulses of $\sim 10$ ns duration. 
Scheme 1. Energy level scheme illustrating the key elementary steps leading to the formation of the long-lived $\mathrm{PhO}^{\circ} / \mathrm{MQH}^{\circ+}$ radical pair and its subsequent decay (see SI pages S21-S32 for details). CPET = concerted proton-electron transfer, ET = electron transfer, $\mathrm{PT}=$ proton transfer, $\mathrm{RDS}=$ rate determining step.

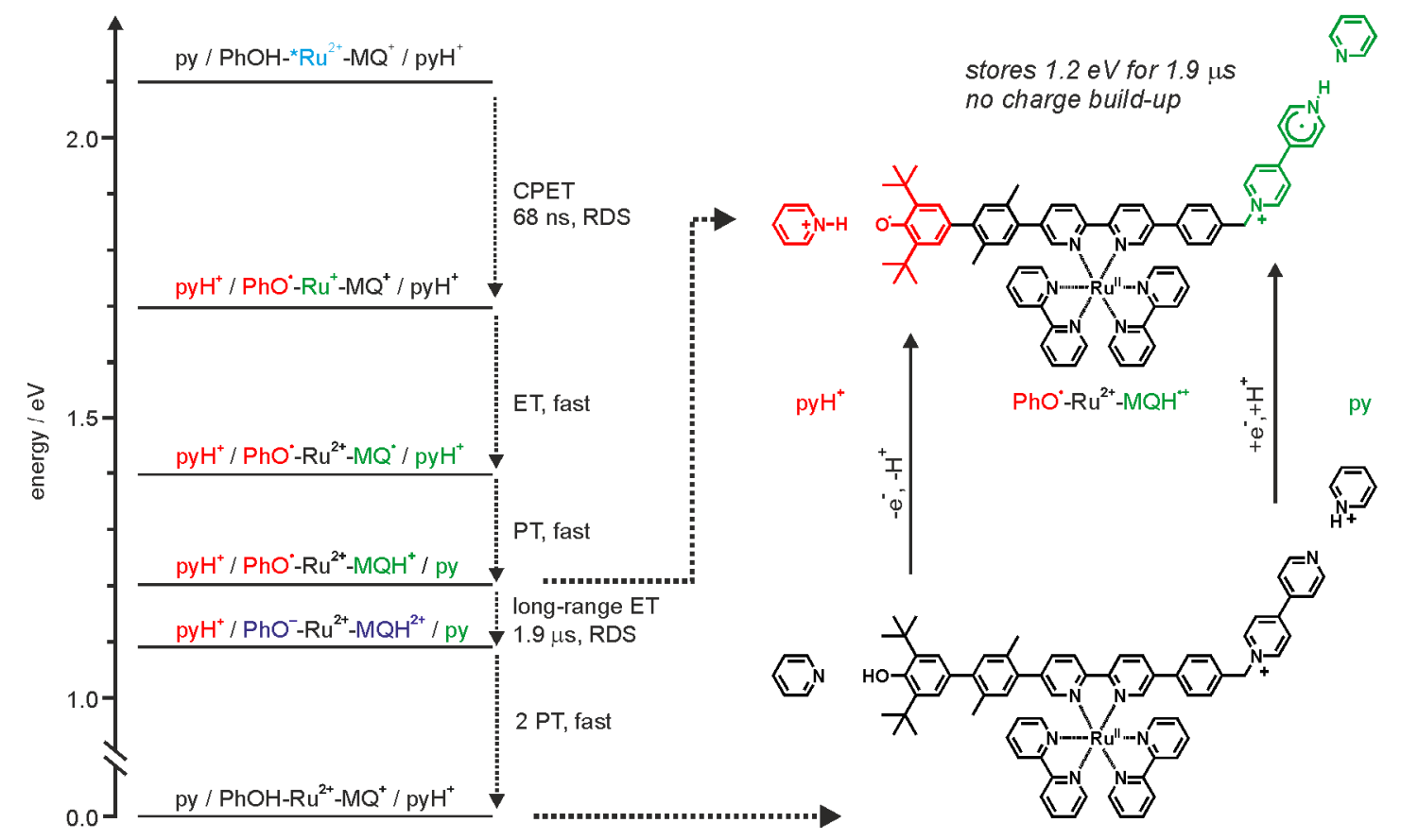

The mechanism for formation and decay of this radical pair state is elucidated in the following. After excitation of the triad at $532 \mathrm{~nm}$ with pulses of $\sim 10 \mathrm{~ns}$ duration, the ${ }^{3}$ MLCT luminescence emitted by the $\mathrm{Ru}(\mathrm{II})$ photosensitizer at $630 \mathrm{~nm}$ in de-aerated py/pyH $\mathrm{H}^{+}$decays in bi-exponential fashion (green trace in Figure 3a) with $\tau=68 \pm 7 \mathrm{~ns}(85 \%)$ and $\tau^{\prime}=780 \pm 80 \mathrm{~ns}$ (15\%). The $\mathrm{MQH}^{*+}$ related transient absorption signals at 395 and $610 \mathrm{~nm}$ rise with $\tau=68 \pm 7 \mathrm{~ns}$ and then decay with $\tau{ }^{\prime}=1.9 \pm 0.2 \mu$ s (green traces in Figure $3 \mathrm{~b} / \mathrm{c}$ ). Thus, $85 \%$ of all excited triads undergo photoreaction to the $\mathrm{PhO}^{\circ}$ and $\mathrm{MQH}^{\circ+}$ products, whereas $15 \%$ exhibit ordinary ${ }^{3} \mathrm{MLCT}$ decay like the isolated $\mathrm{Ru}(\mathrm{bpy})_{3}{ }^{2+}$ complex. In py/pyD ${ }^{+}$where the phenolic moiety of the triad is deuterated, the major ${ }^{3} \mathrm{MLCT}$ luminescence decay component and the rise of the transient absorption signals at $395 / 610 \mathrm{~nm}$ are decelerated to $\tau^{\prime}=150 \pm 15$ ns. Thus, photoproduct formation occurs with an H/D kinetic isotope effect (KIE) of $2.2 \pm 0.2$, indicating that proton motion is involved in the rate-determining reaction step. By contrast, the decay of the photoproduct exhibits no significant KIE $(0.9 \pm 0.2)$.

Oxidative quenching of ${ }^{3} \mathrm{MLCT}$-excited photosensitizer by $\mathrm{MQ}^{+}$is endergonic by $0.2 \mathrm{eV}$ (SI page S29), and even when occurring in concert with proton uptake at the acceptor there is no significant driving-force for this reaction step. The observation of essentially unquenched ${ }^{3} \mathrm{MLCT}$ emission in the $\mathrm{Ru}(\mathrm{II})-\mathrm{MQ}^{+}$reference dyad in $\mathrm{py} / \mathrm{pyH}^{+}$compared to pyridine solution corroborates this interpretation. (SI pages S37-S40). Reductive ${ }^{3}$ MLCT quenching by $\mathrm{PhOH}$ is endergonic by $0.5 \mathrm{eV}$, but concerted PCET yields a driving-force of ca. $-0.4 \mathrm{eV}$ (SI page S29). Thus, it is plausible that reductive quenching by $\mathrm{PhOH}$ with concerted proton release to py is the rate-determining reaction step (uppermost dashed downward arrow in Scheme 1, labeled RDS), in line with the H/D KIE of $2.2 \pm 0.2$ and in agreement with complementary studies in neat pyridine (SI page S33-S34). Subsequent electron transfer from reduced photosensitizer to $\mathrm{MQ}^{+}$is then exergonic by $0.3 \mathrm{eV}$ (second dashed downward arrow in Scheme 1, ' $\mathrm{Ru}^{+}$, denotes $\mathrm{Ru}(\mathrm{bpy})_{3}{ }^{+}$), and protonation of MQ' liberates another 0.2
eV (third dashed downward arrow in Scheme 1) (SI page S29). The final photoproduct observed in Figure 2a stores ca. $1.2 \mathrm{eV}$ (Scheme 1, top right).

Based on the observable $\Delta \mathrm{OD}$ values and the extinction coefficients of the photoproducts, we estimate that $85-90 \%$ of all ${ }^{3}$ MLCT-excited triad molecules reach the radical pair state (SI pages S41-S42), in good agreement with the ${ }^{3}$ MLCT decay behavior discussed above (15\% unquenched ${ }^{3}$ MLCT states).

The relevant acidity constants are such that in the py $/ \mathrm{pyH}^{+}$mixture less than $0.1 \%$ of all triad molecules are expected to be deprotonated at the phenolic donor site (SI page S17-S18), yet in $85-90 \%$ of all excited triads $\mathrm{PhO}^{\circ}$ and $\mathrm{MQH}^{+}$are formed (see above), hence it seems clear that the observable photochemistry originates largely from triad molecules with their phenol moieties initially protonated, not from phenolate species. Furthermore, a dynamic shift of the acid-base equilibrium between $\mathrm{PhOH}$ and py after photoexcitation of the triad can be excluded as a major contributor, because the shift in equilibrium has only a rate constant on the order of $10^{-3}$ to $10^{-1} \mathrm{~s}^{-1}$ (SI page S43) whereas the observable time constant for product formation is several orders of magnitude faster $\left(\tau=68 \pm 7 \mathrm{~ns} ; \tau^{-1} \approx 1.5 \pm 0.2 \cdot 10^{7} \mathrm{~s}^{-1}\right)$.

Thus, we conclude that photoproduct formation proceeds according to the sequence of elementary steps illustrated in Scheme 1. Initial oxidation of $\mathrm{PhOH}$ by ${ }^{3} \mathrm{MLCT}$-excited $\mathrm{Ru}(\mathrm{II})$ sensitizer occurs in concert with proton release to py and is ratedetermining. Subsequent electron transfer from $\mathrm{Ru}(\mathrm{bpy})_{3}{ }^{+}$to $\mathrm{MQ}^{+}$ is followed by protonation of $\mathrm{MQ}^{*}$ by $\mathrm{pyH}^{+}$. The overall PCET chemistry at the monoquat acceptor does not take place in concerted fashion because the initial step of the electron transfer, proton transfer sequence is sufficiently exergonic. The long-lived photoproduct stores ca. $1.2 \mathrm{eV}$ and decays via a rate-determining intramolecular reverse electron transfer from $\mathrm{MQH}^{++}$to $\mathrm{PhO}^{\circ}$, leading to the formation of $\mathrm{MQH}^{2+}$ and $\mathrm{PhO}^{-}$, in line with the absence of a H/D KIE for photoproduct decay. In the py/pyH $\mathrm{pH}^{+}$ mixture, deprotonation of $\mathrm{MQH}^{2+}$ and protonation of $\mathrm{PhO}^{-}$are both rapid, and consequently these intermediates remain unob- 
served in this solvent. Only in neat pyridine can $\mathrm{PhO}^{-}$be detected, as discussed above.

In summary, a single photon is required to drive PCET at both the phenolic donor and the monoquat acceptor, and a sequence of concerted and stepwise PCET processes is involved. The resulting long-lived radical pair state is different from simple electron-hole separation in that the charges of the donor and the acceptor remain unchanged, yet $1.2 \mathrm{eV}$ of light energy are stored.

The stabilization of primary photoproducts resulting from electron transfer by coupled protonation and deprotonation reactions is important for multielectron photochemistry and the accumulation of redox equivalents. A specific key challenge is that once the first electron transfer step has occurred, electrons and holes are prone to recombine rapidly upon secondary photoexcitation. ${ }^{12}$ However, proton uptake at the reduction site and proton release at the donor moiety produces stabilized intermediates which are less prone to recombine upon excitation with a second photon, ${ }^{12-13}$ because there is no charge build-up. PCET photoproducts are therefore more likely to undergo secondary photoinduced electron transfer reactions that lead to the accumulation of oxidative and reductive equivalents. Nature has already implemented this strategy in photosystem $\mathrm{II}^{2}$ and our study represents an important step for artificial systems in that direction.

\section{ASSOCIATED CONTENT}

\section{Supporting Information}

Detailed synthetic protocols and characterization data, description of equipment and methods, supplementary electrochemical and spectroscopic data, and detailed thermochemical discussion (PDF).

\section{AUTHOR INFORMATION}

\section{Corresponding Author}

oliver.wenger@unibas.ch

\section{ACKNOWLEDGMENT}

This work was funded by the Swiss National Science Foundation through grant number 200021_146231/1 and the NCCR Molecular Systems Engineering.

\section{REFERENCES}

(1) (a) Balzani, V., Electron transfer in chemistry 2001, 3. (b) Wasielewski, M. R., Chem. Rev. 1992, 92, 435-461. (c) Yamamoto, M.; Föhlinger, J.; Petersson, J.; Hammarström, L.; Imahori, H., Angew. Chem. Int. Ed. 2017, 56, 3329-3333. (d) Lim, G. N.; Obondi, C. O.; D'Souza, F., Angew. Chem. Int. Ed. 2016, 55, 11517-11521. (e) Hu, K.; Blair, A. D.; Piechota, E. J.; Schauer, P. A.; Sampaio, R. N.; Parlane, F. G. L.; Meyer, G. J.; Berlinguette, C. P., Nat. Chem. 2016, 8, 853-859. (f) Imahori, H.; Tamaki, K.; Guldi, D. M.; Luo, C. P.; Fujitsuka, M.; Ito, O.; Sakata, Y.; Fukuzumi, S., J. Am. Chem. Soc. 2001, 123, 2607-2617. (g) Delor, M.; Keane, T.; Scattergood, P. A.; Sazanovich, I. V.; Greetham, G. M.; Towrie, M.; Meijer, A.; Weinstein, J. A., Nat. Chem. 2015, 7, 689-695.

(2) (a) Renger, G.; Renger, T., Photosynth. Res. 2008, 98, 53-80. (b) Reece, S. Y.; Nocera, D. G., Annu. Rev. Biochem. 2009, 78, 673-699. (c) Dempsey, J. L.; Winkler, J. R.; Gray, H. B., Chem. Rev. 2010, 110, 70247039.

(3) Nelson, N.; Yocum, C. F., Annu. Rev. Plant Biol. 2006, 57, 521-

(4) (a) Glover, S. D.; Parada, G. A.; Markle, T. F.; Ott, S.; Hammarström, L., J. Am. Chem. Soc. 2017, 139, 2090-2101. (b) Magnuson, A.; Berglund, H.; Korall, P.; Hammarström, L.; Åkermark, B.; Styring, S.; Sun, L. C., J. Am. Chem. Soc. 1997, 119, 10720-10725. (c)
Concepcion, J. J.; Brennaman, M. K.; Deyton, J. R.; Lebedeva, N. V.; Forbes, M. D. E.; Papanikolas, J. M.; Meyer, T. J., J. Am. Chem. Soc 2007, 129, 6968-6969. (d) Pizano, A. A.; Yang, J. L.; Nocera, D. G., Chem. Sci. 2012, 3, 2457-2461. (e) Megiatto, J. D.; Mendez-Hernandez, D. D.; Tejeda-Ferrari, M. E.; Teillout, A. L.; Llansola-Portoles, M. J.; Kodis, G.; Poluektov, O. G.; Rajh, T.; Mujica, V.; Groy, T. L.; Gust, D.; Moore, T. A.; Moore, A. L., Nat. Chem. 2014, 6, 423-428. (f) Bonin, J.; Costentin, C.; Robert, M.; Savéant, J. M., Org. Biomol. Chem. 2011, 9, 4064-4069. (g) Wenger, O. S., Acc. Chem. Res. 2013, 46, 1517-1526. (h) Eisenhart, T. T.; Dempsey, J. L., J. Am. Chem. Soc. 2014, 136, 1222112224. (i) Li, H.; Zhang, M. T., Angew. Chem. Int. Ed. 2016, 55, 1313213136. (j) Gagliardi, C. J.; Wang, L.; Dongare, P.; Brennaman, M. K.; Papanikolas, J. M.; Meyer, T. J.; Thompson, D. W., Proc. Natl. Acad. Sci. U. S. A. 2016, 113, 11106-11109. (k) Lachaud, T.; Quaranta, A.; Pellegrin, Y.; Dorlet, P.; Charlot, M. F.; Un, S.; Leibl, W.; Aukauloo, A., Angew. Chem. Int. Ed. 2005, 44, 1536-1540. (1) Biczok, L.; Gupta, N.; Linschitz, H., J. Am. Chem. Soc. 1997, 119, 12601-12609. (m) Arrigo, A.; Nastasi, F.; La Ganga, G.; Puntoriero, F.; Zappalà, G.; Licciardello, A.; Cavazzini, M.; Quici, S.; Campagna, S., Chem. Phys. Lett. 2017, 683, 96-104. (n) Warren, J. J.; Menzeleev, A. R.; Kretchmer, J. S.; Miller, T. F.; Gray, H. B.; Mayer, J. M., J. Phys. Chem. Lett. 2013, 4, 519-523.

(5) (a) Braterman, P. S.; Song, J. I., J. Org. Chem. 1991, 56, 46784682. (b) Das, P. K.; Encinas, M. V.; Steenken, S.; Scaiano, J. C., J. Am. Chem. Soc. 1981, 103, 4162-4166. (c) Manner, V. W.; Markle, T. F.; Freudenthal, J. H.; Roth, J. P.; Mayer, J. M., Chem. Commun. 2008, 256258.

(6) (a) Harriman, A.; Millward, G. R.; Neta, P.; Richoux, M. C.; Thomas, J. M., J. Phys. Chem. 1988, 92, 1286-1290. (b) Shiina, Y.; Oishi, S.; Ishida, H., Tetrahedron Lett. 2012, 53, 1249-1252.

(7) (a) Kuss-Petermann, M.; Wenger, O. S., Angew. Chem. Int. Ed 2016, 55, 815-819. (b) Hankache, J.; Wenger, O. S., Chem. Commun. 2011, 47, 10145-10147. (c) Geiss, B.; Lambert, C., Chem. Commun. 2009, 1670-1672.

(8) (a) Markle, T. F.; Mayer, J. M., Angew. Chem. Int. Ed. 2008, 47, 738-740. (b) Rhile, I. J.; Mayer, J. M., J. Am. Chem. Soc. 2004, 126 , 12718-12719. (c) Costentin, C.; Robert, M.; Savéant, J. M., J. Am. Chem. Soc. 2006, 128, 4552-4553. (d) Costentin, C.; Robert, M.; Savéant, J. M., Acc. Chem. Res. 2010, 43, 1019-1029.

(9) (a) Warren, J. J.; Tronic, T. A.; Mayer, J. M., Chem. Rev. 2010, 110, 6961-7001. (b) Huynh, M. T.; Mora, S. J.; Villalba, M.; TejedaFerrari, M. E.; Liddell, P. A.; Cherry, B. R.; Teillout, A. L.; Machan, C. W.; Kubiak, C. P.; Gust, D.; Moore, T. A.; Hammes-Schiffer, S.; Moore, A. L., ACS Central Sci. 2017, 3, 372-380.

(10) (a) Kuss-Petermann, M.; Wolf, H.; Stalke, D.; Wenger, O. S., J. Am. Chem. Soc. 2012, 134, 12844-12854. (b) Bronner, C.; Wenger, O. S., Phys. Chem. Chem. Phys. 2014, 16, 3617-3622.

(11) (a) Lomoth, R.; Haupl, T.; Johansson, O.; Hammarström, L., Chem.-Eur. J. 2002, 8, 102-110. (b) Yonemoto, E. H.; Saupe, G. B.; Schmehl, R. H.; Hubig, S. M.; Riley, R. L.; Iverson, B. L.; Mallouk, T. E., J. Am. Chem. Soc. 1994, 116, 4786-4795. (c) Mecklenburg, S. L.; Peek, B. M.; Schoonover, J. R.; McCafferty, D. G.; Wall, C. G.; Erickson, B. W.; Meyer, T. J., J. Am. Chem. Soc. 1993, 115, 5479-5495. (d) Kelly, L. A.; Rodgers, M. A. J., J. Phys. Chem. 1995, 99, 13132-13140.

(12) (a) Hammarström, L., Acc. Chem. Res. 2015, 48, 840-850. (b) Pellegrin, Y.; Odobel, F., Coord. Chem. Rev. 2011, 255, 2578-2593. (c) Kuss-Petermann, M.; Wenger, O. S., Helv. Chim. Acta 2017, 100, e1600283.

(13) (a) O'Neil, M. P.; Niemczyk, M. P.; Svec, W. A.; Gosztola, D. Gaines, G. L.; Wasielewski, M. R., Science 1992, 257, 63-65. (b) KussPetermann, M.; Orazietti, M.; Neuburger, M.; Hamm, P.; Wenger, O. S., J. Am. Chem. Soc. 2017, 139, 5225-5232. (c) Wouters, K. L.; de Tacconi, N. R.; Konduri, R.; Lezna, R. O.; MacDonnell, F. M., Photosynth. Res. 2006, 87, 41-55. (d) Zedler, L.; Kupfer, S.; de Moraes, I. R.; Wächtler, M.; Beckert, R.; Schmitt, M.; Popp, J.; Rau, S.; Dietzek, B., Chem.-Eur. J. 2014, 20, 3793-3799. 


\section{Page 5 of 5}

Table of contents

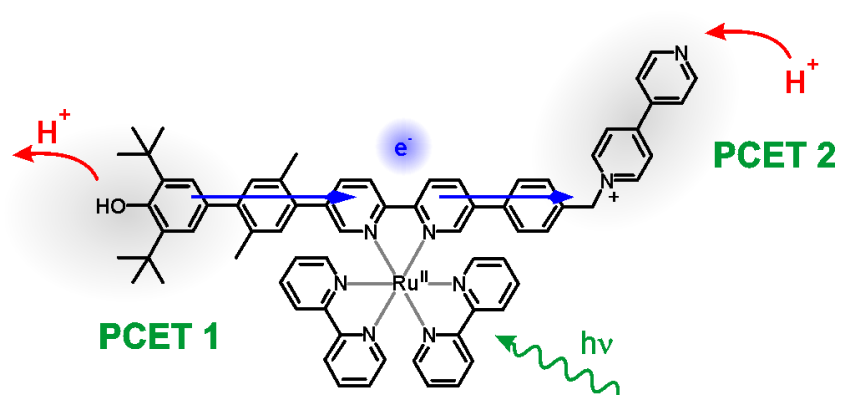

1

2

3

4

5

6

9

10

11

12

13

14

16

17

18

19

20

21

22

23

24

25

26

27

28

29

30

31

32

33

34

35

36

37

38

39

40

41

42

43

44

45

46

47

48

49

50

51

52

53

54

55

56

57

58

59

60 